\title{
AN OPTIMAL UNEMPLOYMENT RATE: COMMENT *
}

\section{John O. BLackburn}

Dobell and Ho have recently presented in this Journal ${ }^{1}$ an aggregate model of the economy in which unemployment may be optimal with respect to a maximum consumption-over-time criterion. They carefully abstract from Phillips curve-type trade-offs involving the price level, or from frictional unemployment. Rather, they extend optimal capital accumulation models to include, in effect, human capital, with training costs and mortality considerations introduced.

Their treatment of investment in training is analogous to wellknown results with respect to investment in physical capital. As is the case with respect to physical capital, there is some level beyond which consumption is diminished by further "human capital" accumulation. Costs of training (analogous to gross saving and investment) exceed returns, so that output remaining for consumption (output less investment in physical capital and less resources used in training) is lower than it might otherwise be. Dobell and Ho conclude that some unemployment (of "untrained" humans) may be consistent with maximum aggregate consumption through time. They mention the possibility of transfer payments to the unemployed, of course, though they are necessarily concerned with questions of production, not distribution.

I should like to point out in this comment that their result rests on several implicit assumptions, and that equally plausible assumptions (within the framework of their model) lead to a full employment result.

Their model implicitly assumes (1) a homogenous (employed and trained) labor force; any worker is like any other. Further, (2) it assumes that training is an all-or-nothing proposition; that each worker is trained to the same level as all other workers or that he is not trained at all. It further assumes (3) that there is only one possible level of training for all workers. ${ }^{2}$ If one keeps the first two

* I am grateful to my colleague, John M. Vernon, for reading a preliminary draft and making a number of helpful suggestions.

1. A. R. Dobell and Y. C. Ho, "An Optimal Unemployment Rate," this Journal, LXXXI (Nov. 1967), 675-83.

2 . The relevant phrase is ". . . we then suppose that there is some function $d(w)$ which, for any employment rate $w(=W / L)$, gives the average capital 
assumptions, but substitutes another for the third, the model will require full employment as an optimal solution, or will require some unemployment, depending on the behavior of returns to training as we proceed to successively higher levels of training.

On any of the consumption-maximizing paths in the Dobell-Ho model, there is implied for each moment in time a "stock" of human capital. Under the implicit assumptions of the model, this optimal "stock" of human capital can be achieved in one and only one way - training the optimal number of "workers" each to the same level, and each worker to the only level considered in the model. Suppose, for example, that the optimal "stock" of human capital at any one moment is 10,000,000 "units." Further suppose that 10 "units" of training represents the only level of training. That is, each worker is "trained" 10 units worth (under cost conditions described in the model) or he is not trained at all. The optimal number of trained workers at that moment is thus $1,000,000$. If the potential work force happened to be $1,200,000$, it would "pay" to have 200,000 individuals untrained and unemployed.

Now let us drop the assumption that there is one and only one level to which each worker is trained, but let us keep the assumptions that all employed labor is homogeneous and that all workers are trained to the same level, whatever that level is. The optimal "stock" of human capital (10,000,000 "units") might be obtained by providing $1,200,000$ workers with 8.33 "units" of training each. If there is a proportional relationship between "units" of training and their productivity, and if the cost per unit of training is not changed by giving fewer units to more people (with the same total number of units produced), then the economy can have both full employment and an optimal "stock" of human capital. If, however, costs per unit of training rise as more people are given fewer units each, some unemployment may continue to be optimal.

Now suppose that there is a kind of diminishing returns to "units" of training. That is, as more and more units of training are pumped into each individual, his efficiency in production rises, but not in proportion to the increase in units of training. ${ }^{3}$ If the $8.33-10$

cost per man to train additions to the work force" (Dobell and Ho, op. cit. p. 677). It is not clear whether the average cost in question refers to (1) situations in which workers are trained to different levels, at different costs, and the average is the average of those differing training costs per man, or (2) average cost per man trained in the "training industry" in the conventional economic sense of the average cost of a homogeneous product. Later statements in the paper imply the latter concept. My argument, developed below, holds, however, for the former concept as well.

3. If "units" of training may be thought of as roughly equivalent to years in school, then there is some empirical support for the kind of diminish- 
unit range considered above lay within the range of diminishing returns, 1,200,000 workers each with 8.33 units of training would have a productive capacity greater than $1,000,000$ workers with 10 units each. As long as the economy remained in such a range of training units, full employment would always be more efficient than underemployment, no matter what the size of the optimal stock of human capital. ${ }^{4}$

We may now relax the assumption that the cost of a unit of training is the same for a given worker whether it is his first, his fifth, or his tenth. ${ }^{5}$ Suppose that successive units of training for a given worker cost more per unit. Then full employment is the optimal state for any required "stock" of human capital if "returns to training" in the sense described above are diminishing or constant. Again if units of training may be roughly compared with years of schooling, there is some empirical support for the proposition that the tenth or twelfth unit costs more than the first or second.

There is one other aspect of the matter which may lead to full employment even under the strict Dobell-Ho assumptions. Let us suppose that "education" and "training" are somewhat different but not wholly separable activities. Dobell and Ho are humanitarians; they suggest that transfer payments might be made to the "unemployables," perhaps even so generously as to make their per capita consumption outlay equal to the national average. Now "education" has consumption as well as investment aspects, and the "unemployables" might wish to expend some of their incomes on education. Having got some education, the additional, purely "training" outlay might be sufficiently small to make their employment profitable.

\section{DUKe UNIVERSITY}

ing returns assumed. See G. S. Becker, Human Capital (New York: National Bureau of Economic Research, 1964), p. 155. Private returns from elementary education apparently exceed those from high school education, which in turn exceed those from college education. One has positive returns from continuing his education, of course, but they may diminish. This finding is qualified, however, when Becker attempts to adjust for ability differentials.

4. Unless the economies involved in more persons with fewer units of training were more than offset by higher training costs per unit (total units trained the same, but more people with fewer units each).

5. Note that we are not speaking of costs varying with the level of output of units of training, which kind of variation Dobell and Ho explicitly consider. We are considering, rather, that the number of units of training is given (units $x$ number of workers trained) and asking whether, for any given worker, the first unit has a different cost from a further unit. 